\title{
Isotope-Dilution Mass Spectrometry for Quantification of Urinary Active Androgens Separated by Gas Chromatography
}

\author{
Su Hyeon Lee ${ }^{\mathrm{a}, \mathrm{b}}$, Man Ho Choi ${ }^{\mathrm{a}}$, Won-Yong Lee ${ }^{\mathrm{b}}$, and Bong Chul Chung,* \\ ${ }^{a}$ Life/Health Division, Korean Institute of Science and Technology, Seoul 136-791, Korea \\ ${ }^{b}$ Department of Chemistry, Yonsei University, Seoul 120-749, Korea
}

Received November 14, 2010; Revised November 25, 2010; Accepted November 27, 2010

First published on the web December 15, 2010; DOI: 10.5478/MSL.2010.1.1.029

\begin{abstract}
Cross reacting antibodies can cause an overestimation of the results of immunoassays. Therefore, alternative methods are needed for the accurate quantification of steroids. Gas chromatography combined with isotope-dilution mass spectrometry (GC-IDMS) is developed to quantify urinary active androgens, testosterone, epitestosterone and dihydrotestosterone, which are clinically relevant androgens to both hair-loss and prostate diseases. The method devised involves enzymatic hydrolysis with $\beta$ glucuronidase, solid-phase extraction, liquid-liquid extraction using methyl tert-butyl ether and subsequent conversion to pentafluorophenyldimethylsilyl-trimethylsilyl (flophemesyl-TMS) derivatives for sensitive and selective analysis in selected-ion monitoring mode. Flophemesyl-TMS derivatization not only eliminates matrix interference but also has a good peak resolution within a 6 min-run. A selective and sensitive GC technique with flophemesyl-TMS derivatives also allows accurate quantitative analysis of three active androgens when combined with IDMS. The limit of quantification of the three analytes was $<50 \mathrm{pg} / \mathrm{mL}$, and extraction recoveries ranged from 91.9 to $102.1 \%$. The precision and accuracy were $1.2 \sim 6.5 \%$ and $89.0 \sim 106.7 \%$, respectively. This GC-IDMS method can be useful for evaluating the drug efficacy and monitoring the biological processes responsible for male-pattern baldness and prostate diseases.
\end{abstract}

Key words: Androgen, Testosterone, Isotope-dilution, GC-MS, Drug efficacy

\section{Introduction}

Androgens regulate human hair growth, and the hair-loss is mediated by dihydrotestosterone (DHT), which is metabolized from testosterone catalyzed by $5 \alpha$-reductase. Epitestosterone, as the 17-epimer of testosterone, might inhibit the activity of DHT. ${ }^{1-3}$ In androgen-dependent neoplasms, the growth of the prostate gland relies on these active androgens. ${ }^{4,5}$ Although there are many reports dealing with the actions of androgen in hair-loss and prostate diseases, the metabolic relationship between the three active androgens mentioned above is unclear. Therefore, a direct quantitative technique of the three active androgens is necessary to understand their biochemical roles in androgen-dependent diseases.

In routine clinical screening, radioimmuno- and enzyme immune-assays have advantages but they are not selective in small molecule analyses, which can result in an overestimation due to the cross-reactions of antibodies. ${ }^{6,7}$ In contrast, gas chromatography-mass spectrometry (GC-MS) based techniques show better quantitative reproducibility and GC-MS profiling is used widely for steroid analysis. ${ }^{8-10}$

Isotope-dilution mass spectrometry (IDMS) is the primary method with an adjusted isotope labeled standard, and can minimize run-to-run variations. ${ }^{11-13}$ In an isotope dilution

\footnotetext{
*Reprint requests to Dr. Bong Chul Chung

E-mail: bcc0319@kist.re.kr
}

assay, both the accuracy and precision are potentially improved against other calibration methods due to compensation by identical losses and correcting matrix effects. ${ }^{14}$ Owing to its reproducibility, IDMS is a well-established reference measurement principle in small molecular diagnostic tools in clinical applications without the need for quantitative calibration curves. ${ }^{15}$ An accurate and precise measurement of three urinary active androgens as their flophemesyl-TMS derivatives, which could increase peak selectivity in GC-MS analysis, was developed. The GC-IDMS method validated was applied to the quantitative urinary active androgens obtained from patients with hair-loss because these three androgens play an important role in hair-loss. ${ }^{13}$

\section{Chemicals}

Reference standards of the three active androgens examined in this study were obtained from Steraloids (Newport, RI, USA). The internal standards (ISTDs), $16,16,17-d_{3}$-testosterone, $16,16,17-d_{3}$-epiterstosterone and $16,16,17-d_{3}$-DHT were purchased from NARL (Sydney, Australia). For solid-phase extraction (SPE), the Oasis HLB cartridge ( $3 \mathrm{~mL}, 60 \mathrm{mg}$ ) was supplied by Waters (Milford, MA, USA) and $\beta$-glucuronidase (aqueous solution stabilized with 50\% glycerol) for enzymatic hydrolysis was purchased from Roche (Mannheim, Germany). Sodium phosphate monobasic, sodium phosphate dibasic and potassium carbonate were acquired from Sigma (St. Louis, MO, USA). The derivatizing agents, $N$-methyl- $N$-trifluorotrimethylsilyl 
acetamide (MSTFA), flophemesyl chloride, ammonium iodide $\left(\mathrm{NH}_{4} \mathrm{I}\right)$, and dithioerythritol (DTE), were also purchased from Sigma. All organic solvents were of analytical or HPLC grade and purchased from Burdick \& Jackson (Muskegan, MI, USA). Deionized water was prepared using a Milli-Q purification system (Millipore, Billerica, MA, USA).

\section{Standard solutions and quality-control samples}

Stock solutions of all reference standards were dissolved in methanol at $1 \mathrm{mg} / \mathrm{mL}$, and working solutions were made up with methanol at concentrations ranging from 0.01 to $10 \mu \mathrm{g} / \mathrm{mL}$. All standard solutions were stored at $-20{ }^{\circ} \mathrm{C}$ until needed. To optimize and validate the method, steroid-free urine was first prepared using a previously described method. ${ }^{10}$ The quality-control (QC) samples were prepared at five different molar ratios $(0.2,0.5,1.0$, 2.0, and 4.0) in steroid-free urine spiked with three androgens.

\section{Subjects and sample-collection}

Urine samples were obtained from 130 men (age; $30.4 \pm 5.4 \mathrm{yr}$ ) and 14 women (age; $32.5 \pm 8.1 \mathrm{yr}$ ) patients with hair-loss at the Murisaem Oriental Medical Clinic (Seoul, Korea). All samples were stored at $-20{ }^{\circ} \mathrm{C}$ until needed.

\section{Sample preparation}

Androgen analysis was based on previous reports. ${ }^{10}$ Briefly, the urine samples $(2 \mathrm{~mL})$ were spiked with $40 \mu \mathrm{L}$ of three ISTDs ( $d_{3}$-testosterone; $1 \mu \mathrm{g} / \mathrm{mL}, d_{3}$-epitestosterone; $1 \mu \mathrm{g} / \mathrm{mL}, d_{3}$ DHT; $0.5 \mu \mathrm{g} / \mathrm{mL}$ ) and $1 \mathrm{~mL}$ of $0.2 \mathrm{M}$ phosphate buffer ( $\mathrm{pH} 7.2$ ) and $50 \mu \mathrm{L}$ of $\beta$-glucuronidase were then added. After enzymatic hydrolysis at $55^{\circ} \mathrm{C}$ for $1 \mathrm{~h}$ the samples were extracted using the Oasis HLB ${ }^{\mathrm{TM}}$ SPE cartridges coupled to a peristaltic pump to improve the extraction efficiency during the SPE process. After loading a sample onto a cartridge, the cartridge was washed with $2 \mathrm{~mL}$ water and eluted twice with $2 \mathrm{~mL}$ of methanol. Combined methanol eluents were evaporated under a nitrogen stream, and $1 \mathrm{~mL}$ of $0.2 \mathrm{M}$ phosphate buffer $(\mathrm{pH} 7.2)$ and $500 \mu \mathrm{L}$ of $5 \%$ potassium carbonate were then added. The solution was extracted twice with $2.5 \mathrm{~mL}$ of methyl tertbutyl ether (MTBE) and the eluted organic solvents were evaporated using a $\mathrm{N}_{2}$ evaporator at $40{ }^{\circ} \mathrm{C}$. A flophemesyl chloride solution $(50 \mu \mathrm{L})$ was added to the dried residue and incubated at room temperature for $15 \mathrm{~min}$. After evaporating the reaction solution under nitrogen at $70^{\circ} \mathrm{C}$, the residue was derivatized with MSTFA/ $\mathrm{NH}_{4} \mathrm{I} / \mathrm{DTE}(40 \mu \mathrm{L} ; 500: 4: 2$, v/w/ w) at $60{ }^{\circ} \mathrm{C}$ for $20 \mathrm{~min}$, and $2 \mu \mathrm{L}$ of the resulting mixture was subjected to GC-MS in selected-ion monitoring (SIM) mode.

\section{Instrumental conditions}

GC-MS analysis was performed using an Agilent 6890 Plus gas chromatograph interfaced with a single-quadrupole Agilent $5975 \mathrm{MSD}$ at an electron energy of $70 \mathrm{eV}$. Each sample $(2 \mu \mathrm{L})$ was injected in split mode $(8: 1)$ at $280{ }^{\circ} \mathrm{C}$ with helium as the carrier gas at $234.42 \mathrm{kPa}(0.8 \mathrm{~mL} / \mathrm{min})$ in a constant flow-rate and separated through an Ultra-1 capillary column $(25 \mathrm{~m} \times 0.2 \mathrm{~mm}$ i.d., $0.33 \mu \mathrm{m}$ film thickness; Agilent Technologies; Palo Alto, CA, USA). The GC oven temperature was initially set to $280{ }^{\circ} \mathrm{C}$, increased to $320{ }^{\circ} \mathrm{C}$ at $8{ }^{\circ} \mathrm{C} / \mathrm{min}$ and held at that temperature for $6 \mathrm{~min}$ with an ion source temperature of $230{ }^{\circ} \mathrm{C}$. For quantitative analysis, the characteristic ions of each androgen were determined as their flophemesyl-TMS derivatives. The peak identifications were achieved by comparing the retention times and matching the area ratios of the characteristic ions (Table 1).

\section{Method validation}

QC samples containing the active androgens were quantified using the peak area ratios versus the corresponding ISTD for the three active androgens. The limits of detection (LOD) and quantification (LOQ) were defined as the lowest concentration with a signal-to-noise $(\mathrm{S} / \mathrm{N})$ ratio $>3$ and 10 , respectively. Five samples at five different molar ratios $(0.2$, $0.5,1,2$ and 4) for the three active androgens are analyzed using the same procedures separately. The precision and accuracy are expressed as the coefficients of the variation (\% CV) and percentage relative errors ( $\%$ bias), respectively. The intra- and inter-day assays were determined by analyzing five replicates and running the samples on five different days.

The extraction recoveries were determined using the QC samples at five different molar ratios by adding known amounts of analytes to the steroid-free urine samples. The difference between the sample and spiked sample was determined and the percentage recovery was calculated.

\section{Results and Discussion}

\section{Optimization of sample preparation}

Most urinary androgens in humans were excreted mainly as their glucuronic and sulfuric conjugates, and their concentration can be evaluated after enzymatic hydrolysis. $\beta$-glucuronidase hydrolysis was introduced in this study due to the production of by-products of $3 \beta$-hydroxy-5-ene steroids by hydrolysis with $\beta$-glucuronidase/arylulfatase. ${ }^{10}$ The following two extraction conditions were examined either after SPE or before enzymatic hydrolysis. The overall extraction yields were similar for testosterone and epitestosterone, whereas DHT was slightly increased with SPE after hydrolysis. Therefore, enzymatic hydrolysis was processed first in sample preparation.

After SPE, urinary steroids were re-extracted with different organic solvents, such as ethylether, MTBE, ethylacetate, $2: 3$ ethylacetate/n-hexane (v/v), and $n$-hexane after adjusted $\mathrm{pH} 10.5$ using $0.5 \mathrm{~mL}$ of $5 \% \mathrm{~K}_{2} \mathrm{CO}_{3}$ solution to maximize extraction recovery. Although all solvents tested had good extraction efficiencies, MTBE was finally selected because of the diminished urinary interference and maximized extraction recoveries (Supplementary Table 1).

\section{Optimization of derivatization method}

The three active androgens have two ionizable hydrogen atoms in their chemical structures. To improve the GC properties, 
the androgens were trimethylsilylated but epitestosterone was co-eluted with an endogenous steroid, androstanedione, which has the same molecular mass and similar MS fragments as their 3,17-TMS derivatives under the present GC conditions. TMS derivatization at only the 17-carbon of the androgens studied was tested with MSTFA containing 1\% trimethylchlorosilane. However, both testosterone and epitestosterone revealed the presence of two peaks corresponding to 17-TMS and 3,17TMS derivatives. This can be explained by a reaction at the 3-enol keto position during GC injection in the high-temperature injection port. ${ }^{16}$ In contrast, the mixed derivatization with flophemesyl chloride and MSTFA: $\mathrm{NH}_{4} \mathrm{I}$ :DTE produced 3TMS-17-flophemesyl derivatives without any unexpected peaks, and they showed molecular ions as the base peaks (Figure. 1), which were helpful for increasing both the selectivity and sensitivity. In all mass spectra, the loss of a methyl group led to $[\mathrm{M}-15]^{+}$ions and most peaks were diminished because of the intense molecular ions.

\section{Validated the GC-IDMS analysis}

The use of internal standards in combination with isotopelabeled materials forms the basis of the GC-IDMS technique. The present GC-IDMS analysis was performed using three isotope labeled androgens corresponding to testosterone, epitestosterone and DHT as their flophemesyl-TMS derivatives, which were well separated within $11 \mathrm{~min}$ and quantified precisely in the SIM mode according to the IDMS principle (Table 1). The urinary concentration (C) of each androgen

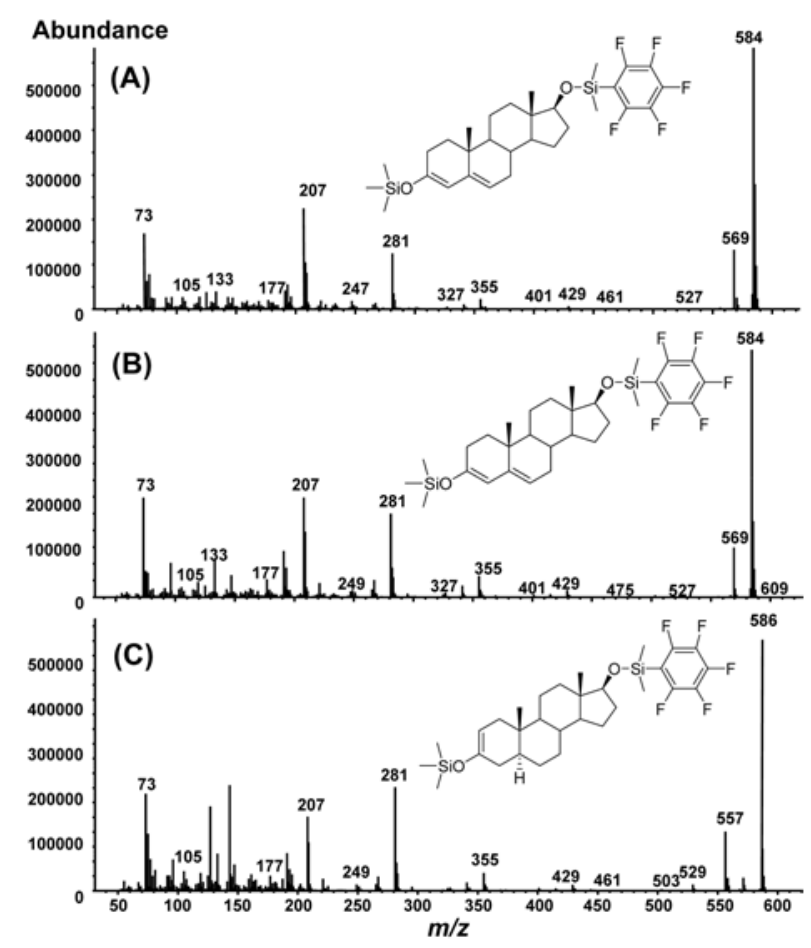

Figure 1. Mass spectra of 3-trimethylsilyl-17-flophemesyl deribatives of (A) testosterone, (B) epitestosterone, and (C) DHT.
Table 1. Peak identity and characteristic ions of active androgens

\begin{tabular}{lcc}
\hline \hline \multicolumn{1}{c}{ Steroid } & Ion selected $(\mathrm{m} / \mathrm{z})$ & Retention time $(\mathrm{min})$ \\
\hline Epitestosterone & $\underline{\mathbf{5 8 4}}, 569$ & 4.93 \\
DHT & $\underline{\mathbf{5 8 6}}, 557$ & 5.34 \\
Testosterone & $\underline{\mathbf{5 8 4}}, 569$ & 5.49 \\
$d_{3}$-epitestosterone & 587 & 4.92 \\
$d_{3}$-DHT & 589 & 5.33 \\
$d_{3}$-testosterone & 587 & 5.48 \\
\hline
\end{tabular}

*Quantitative ions are underlined

was calculated using the following equation: $\mathrm{C}=(\mathrm{RM} \times \mathrm{L}) / \mathrm{M}$, where $\mathrm{M}$ is the mass of the urine sample, $\mathrm{L}$ is the mass of the labeled androgen added to the sample, and RM is the calculated mass ratio. The measurement error was $<4 \%$ in the one-point calibration technique by comparing the molar ratio of unlabeled to labeled analytes (Supplementary Figure 1).

The QC samples were spiked with the unlabeled materials at five different unlabeled to labeled androgen molar ratios $(0.2,0.4,1,2$ and 4$)$ against $40 \mathrm{ng}$ for testosterone and epitestosterone, and $20 \mathrm{ng}$ for DHT (Table 2). Testosterone and epitestosterone had an LOQ of $0.01 \mathrm{ng} / \mathrm{mL}$, whereas DHT could quantify urinary concentrations down to $0.05 \mathrm{ng} / \mathrm{mL}$. The GC-IDMS assay precisions and accuracies were determined by analyzing the QC samples prepared. The intra-day $(n=5)$ precision $(\% \mathrm{CV})$ ranged from 4.5 to $6.5 \%$, and the accuracy ( $\%$ bias) ranged from 89.7 to $102.0 \%$. The inter-day $(n=5)$ precision and accuracy ranged from 1.2 to $2.9 \%$ and 89.0 to $106.7 \%$, respectively. The overall recoveries were from $91.9 \pm 4.3 \sim 102.1 \pm 5.1$ for three active androgens studied.

\section{Quantification of urinary androgens in human}

The validated GC-IDMS based quantitative assay was used to evaluate the urinary levels of active androgens obtained from 130 patients with male or female-pattern baldness. Although it was not the aim of this study to identify the clinical implications, the DHT to testosterone ratio, which reflects the $5 \beta$-reductase enzyme activity, ${ }^{10,17}$ was also evaluated. In human samples, the urinary levels (mean $\pm \mathrm{SD}$ ) of testosterone, epitestosterone and DHT were $1.3 \pm 1.9 \mathrm{ng} / \mathrm{mL}, 9.8 \pm 10.5 \mathrm{ng} / \mathrm{mL}$ and $1.3 \pm 0.9 \mathrm{ng} / \mathrm{mL}$, respectively. The activity of $5 \beta$-reductase was $1.7 \pm 2.0$.

\section{Conclusions}

An improved GC-MS based quantification was developed to meet the clinical requirement for precise quantification of urinary active androgens. Improved GC-MS properties were obtained by mixed 3-TMS-17-flophemesyl derivatization, which eliminated background interference and increased the peak selectivity in the high mass range. The devised method showed good sensitivity at sub-ng/mL urinary concentrations and can be useful in clinical applications, particularly in investigating androgen dependent diseases, as well as in 
Su Hyeon Lee, Man Ho Choi, Won-Yong Lee, and Bong Chul Chung

Table 2. Results of intra- and inter-day validation of the 3 urinary active androgens

\begin{tabular}{|c|c|c|c|c|c|c|}
\hline \multirow{2}{*}{ Steroid } & \multirow{2}{*}{$\begin{array}{l}\text { Molar } \\
\text { ratio }\end{array}$} & \multirow{2}{*}{$\begin{array}{l}\text { Conc. } \\
\text { (ng/mL) }\end{array}$} & \multicolumn{3}{|c|}{ Intra-day $(n=5)$} & \multirow{2}{*}{$\begin{array}{c}\text { Inter-day }(n=5) \\
\text { Precision }(\% \mathrm{CV})\end{array}$} \\
\hline & & & Accuracy ( $\%$ bias $)$ & Precision $(\% \mathrm{CV})$ & Accuracy ( $\%$ bias $)$ & \\
\hline \multirow{5}{*}{ Testosterone } & 0.2 & 4 & 92.8 & 5.0 & 89.0 & 2.9 \\
\hline & 0.5 & 10 & 100.9 & 5.0 & 101.6 & 2.2 \\
\hline & 1 & 20 & 101.9 & 4.7 & 104.9 & 1.5 \\
\hline & 2 & 40 & 99.9 & 5.3 & 104.3 & 1.8 \\
\hline & 4 & 80 & 93.1 & 6.5 & 97.4 & 1.7 \\
\hline \multirow{5}{*}{ Epitestosterone } & 0.2 & 4 & 90.9 & 4.5 & 90.5 & 2.5 \\
\hline & 0.5 & 10 & 101.4 & 5.2 & 103.8 & 1.7 \\
\hline & 1 & 20 & 102.2 & 4.9 & 106.7 & 1.2 \\
\hline & 2 & 40 & 100.1 & 4.6 & 105.2 & 1.6 \\
\hline & 4 & 80 & 93.7 & 6.1 & 98.1 & 1.7 \\
\hline \multirow{5}{*}{ DHT } & 0.2 & 2 & 91.9 & 5.6 & 97.7 & 2.7 \\
\hline & 0.5 & 5 & 101.4 & 4.8 & 105.2 & 1.2 \\
\hline & 1 & 10 & 102.3 & 5.1 & 106.0 & 2.0 \\
\hline & 2 & 20 & 99.6 & 4.8 & 104.3 & 1.9 \\
\hline & 4 & 40 & 94.2 & 6.2 & 98.0 & 2.0 \\
\hline
\end{tabular}

evaluating the drug efficacy responsible for male-pattern baldness and prostate diseases related to androgenic activity.

\section{Acknowledgements}

This study was supported by an intramural grant from the Korean Institute of Science and Technology (KIST), and by grants from the National R\&D Program of the Korean Ministry of Education, Science and Technology (MEST) and the Korean Science and Engineering Foundation (KOSEF).

\section{References}

1. Nuck, B. A.; Lucky A. W. J. Invest. Dermatol. 1987, 89, 209.

2. Starka, L. Endocr. Regul. 1993, 27, 43.

3. Choi, M. H.; Yoo, Y. S.; Chung, B. C. J. Invest. Dermatol. 2001, 116, 57.

4. Choi, M. H.; Kim, J. N.; Chung, B. C. Clin. Chem. 2003, $49,322$.

5. Luu-The, V.; Belanger, A.; Labrie, F. Best Pract, Res. Clin. Endocrinol. Metabol. 2008, 22, 207.

6. Taieb, J.; Mathian, B.; Millot, F.; Patricot, M. C.; Mathieu, E.; Queyrel, N.; Lacroix, I.; Somma-Delpero, C.; Boudou, P. Clin. Chem. 2003, 49, 1381.

7. Wang, C.; Catlin, D. H.; Starcevic, B.; Leung, A.; DiStefano,
E.; Lucas, G.; Hull, L.; Swerdloff, R. S. J. Clin. Endocrinol. Metab. 2004, 89, 2936.

8. Moon, J.-Y.; Jung, H.-J.; Moon, M. H.; Chung, B. C.; Choi. M. H. Steroids 2008, 73, 1090.

9. Moon, J.-Y.; Ha, Y. W.; Moon, M. H.; Chung, B. C.; Choi, M. H. Cancer Epidemiol. Biomarkers Prev. 2010, 19, 388.

10. Moon, J.-Y.; Jung, H.-J.; Moon, M. H.; Chung, B. C.; Choi, M. H. J. Am. Soc. Mass Spectrom. 2009, 20, 1626.

11. Van Uytfanghe, K.; Stöckl, D.; Kaufman, J. M.; Fiers, T.; Ross, H. A.; De Leenheer, A. P.; Thienpont, L. M. Clin. Chem. 2004, 50, 2101.

12. Cawood, M. L.; Field, H. P.; Ford, C. G.; Gillingwater, S.; Kicman, A.; Cowan, D.; Barth, J. H. Clin. Chem. 2005, $51,1472$.

13. Tai, S. S.; Xu, B.; Welch, M. J.; Phinney, K. W. Anal. Bioanal. Chem. 2007, 388, 1087.

14. Wang, W.; Zhou, H.; Lin, H.; Roy, S.; Shaler, T. A.; Hill, L. R.; Norton, S.; Kumar, P.; Anderle, M.; Becker, C. H. Anal. Chem. 2003, 75, 4818

15. Thienpont, L. M.; De Brabandere, V. I.; Stöckl, D.; De Leenheer, A. P. Anal. Chem. 1994, 15, 4116.

16. Choi, M. H.; Kim, J. Y.; Chung, B. C. Analyst 1999, 124, 675.

17. Ha, Y. W.; Moon, J.-Y.; Jung, H.-J.; Chung, B. C.; Choi, M. H. J. Chromatogr. B 2009, 877, 4125. 